\title{
LIBERALIZACIÓN O FOCALIZACIÓN DE LOS COMBUSTIBLES: EXPERIENCIA ECUATORIANA.
}

\section{LIBERALIZATION OR FOCUSING OF FUELS: ECUADORIAN EXPERIENCE}

\author{
Guido Omar Macas Acosta, Mgtr. \\ Magíster en Negocios Internacionales y Gestión de Comercio Exterior (Ecuador). \\ Docente Tiempo Completo de la Facultad de Ciencias Económicas y Empresariales de la \\ Universidad Tecnológica ECOTEC, Ecuador. \\ gmacas@ecotec.edu.ec
}

\section{ARTÍCULO DE REFLEXIÓN}

Recibido: 11 de septiembre de 2019.

Aceptado: 30 de noviembre de 2019.

\section{RESUMEN}

La investigación sobre la liberalización o focalización de los combustibles sobre experiencia ecuatoriana, se centra en analizar la conveniencia o no de aplicar subsidios o su eliminación total o gradual, en la economía, y cómo juega un papel clave la apreciación política de los gobernantes. Se trata de una investigación descriptiva y correlacional, debido a que se busca de forma adecuada especificar características del fenómeno a investigar para poder describir tendencias del grupo de datos que forman las variables y correlacional porque se analiza la relación del subsidio de la gasolina con la demanda y precio del mismo. Este trabajo, busca en primera parte revisar como la medida de eliminar el subsidio a la gasolina súper y reducir la ayuda monetaria a la eco y extra tuvo sus resultados deseados en el corto, mediano y largo plazo. $Y$ si bien en los primeros meses, los gastos en subsidios se redujeron luego tomó una tendencia creciente que es muy probable que en los próximos meses vuelva los niveles anteriores. Lo que evidencia que fue una medida parche y que no solucionó en nada la caja fiscal del Estado.

Palabras clave: Subsidios, precios de los combustibles, barril de petróleo. 


\section{ABSTRACT}

The research on the liberalization or focus of fuels on Ecuadorian experience, focuses on analyzing the convenience or not of applying subsidies, their total or gradual elimination, in the economy, and how the political appreciation of the rulers plays a key role. This is a descriptive and correlational investigation, because it is properly sought to specify characteristics of the phenomenon to be investigated in order to describe trends in the group of data that form the variables and correlational because the relationship between gasoline subsidy and demand is analyzed and the price of it. This work, in the first part, seeks to review how the measure of eliminating the subsidy for super gasoline and reducing monetary aid to the eco and extra had its desired results in the short, medium and long term. And although in the first months, the expenses in subsidies were reduced then it took a growing trend that it is very probable that in the next months the previous levels will return. What evidences that it was a patch measure and that it did not solve at all the fiscal box of the State.

Keywords: Subsidies, fuel prices, barrel of oil.

\section{INTRODUCCIÓN}

El factor clave para el desarrollo de los países como el nuestro es una buena toma de decisiones en lo que concierne a las políticas públicas, y en especial a la aplicación de subsidios o su eliminación total o gradual, la que en sus momentos propicios juega un papel muy importante en la apreciación política de los gobernantes. Es así que se mantienen diversas estrategias en marcha como por ejemplo el de "castigar" a los más pudientes con impuestos muy altos, para con ello financiar los gastos en inversión social, o los también denominados subsidios para ayudar a los que menos tienen. De igual manera está la otra cara de la moneda en donde no se necesitan de estos impuestos altos, sino más bien de un país de una mayor expansión económica con mayores niveles de inversión productiva, controles para reducir el contrabando; entre otras opciones.

Es por tal motivo que se pone en tela de duda si los subsidios están alcanzando los objetivos deseados de beneficiar a los sectores más vulnerables o si solo se los utiliza para un beneficio específico de cierto sector.

En Ecuador, los subsidios se los conocen como "inversión social" y estos tenido una permanencia constante en el tiempo en varias vías, estos se pueden canalizar a través de la oferta subvencionando parte de los costos de producción así se puede adquirir un bien o 
servicio inferior al precio de mercado; o de la demanda que es cuando se incrementan los ingresos del receptor para que se pueda financiera y poder así mismo adquirir ese bien o servicio. Y la ayuda estatal más delicada y sensible son los derivados del petróleo, donde cada Gobierno de los últimos 30 años ha tomado medidas tibias para solucionarlo. Su reducción gradual o total debe ser una opción bien sustentada para no caer en errores y seguir con los problemas fiscales. Y llegar a una liberalización de precios atada a la volatilidad de los mercados internacionales debe ser también de análisis y revisión técnica para que la medicina no sea peor que la enfermedad. Este trabajo, busca en primera parte revisar como la medida de eliminar el subsidio a la gasolina súper y reducir la ayuda monetaria a la eco y extra tuvo sus resultados deseados en el corto, mediano y largo plazo. $Y$ si bien en los primeros meses, los gastos en subsidios se redujeron luego tomó una tendencia creciente que es muy probable que en los próximos meses vuelva los niveles anteriores. Lo que evidencia que fue una medida parche y que no solucionó en nada la caja fiscal del Estado.

\section{REVISIÓN TEÓRICA}

La estructura económica, de los países petroleros, no pueden mantener a largo plazo los precios reales de sus derivados, por lo que deben constantemente aplicar subsidios energéticos para no afectar a los habitantes de recursos económicos limitados. Eso cada año aumenta los gastos y genera problemas de liquidez en sus flujos de caja.

Según (OLADE, 2007) un subsidio energético se refiere a una prestación pública asistencial de carácter económico (en dinero o en especie) a un productor o a un consumidor de la energía durante un tiempo.

Para Riedy (2001) los subsidios comprenden todas las medidas que mantienen el precio para los consumidores debajo del nivel de mercado o para los productores, por encima de él; o que reducen el costo para los consumidores o productores otorgándoles un soporte indirecto. Finalmente, para Bruce (1990) la definición de un subsidio depende del tratamiento que se quiera tener de él, dado que puede ser definido en una forma amplia o muy restringida.

Por tanto, el subsidio es considerado como una herramienta que usan los países para evitar el impacto de los precios dados por el mercado en condiciones normales, dando como consecuencia una alteración a su comportamiento natural asumiendo el costo diferencial el Estado que realiza la política de subsidios (Atkinson, 2015). 
Para otros investigadores se trata de gastos rentista que buscan mantener bajos los precios nacionales de la gasolina y mantenerse en el poder o ganar réditos políticos. Pues muchas de las empresas petroleras son nacionalizadas y venden gasolina en sus países a tasas muy por debajo del mercado internacional (Fails, 2019).

En algunos casos, según los reportes de la Corporación Alemana para la Cooperación Internacional son casi económicamente bajos la venta de combustibles; en 2014, un litro de gasolina en Venezuela costó menos de $\$ 0.02$, aproximadamente ochenta y siete veces más bajo que el promedio mundial del año. Aunque es un ejemplo extremo, los productores de petróleo venden gasolina a tasas más bajas que los productores no petroleros en general (Cheon, Urpelainen y Lackner, 2013)

La idea es que con estos valores se permita generar condiciones equitativas, a través del mercado de bienes y servicios y así garantizar la satisfacción de necesidades energéticas básicas de los sectores de menores recursos a un costo razonable desde el punto de vista de su capacidad de pago.

Esto se origina en algunos casos, porque la extracción fácil de petróleo que provoca los precios bajos internos, aunque esta decisión cuesta a los gobiernos miles de millones en ingresos no percibidos. $Y$ la situación se complica porque hay algunos gobiernos que también proporcionan a los proveedores de gasolina pagos directos de los presupuestos centrales (o en algunos casos, sub nacionales o locales). La Compañía Nacional de Petróleo de Irán recibe una compensación del gobierno para cubrir la diferencia entre los costos de la gasolina importada y el precio interno (artificialmente bajo) obligatorio para los consumidores (FMl 2008).

Los gobiernos centrales también absorben los costos clave de la producción de gasolina directamente, a través de fondos de estabilización que compensan las brechas de precios entre la gasolina importada y los costos de las materias primas, como en Brasil hasta la década de 1980, o actualmente en Nigeria. Ecuador también creó sus fondos petroleros. Como era de esperar, estos desplazan a otras prioridades de gasto y pueden dar lugar a déficits paralizantes. Por ejemplo, Yemen gasta más subsidios al consumo doméstico de gasolina (14 por ciento del producto interno bruto en 2008) que en todas las demás infraestructuras y servicios sociales combinados (Clements, Coady, Fabrizio, Gupta, Alleyne y Sdralevich, 2013).

Y cuando los estados productores de petróleo carecen de capacidades de refinamiento suficientes y más todavía cuando los beneficiarios son consumidores de medianos y altos 
ingresos, los problemas de liquidez son mayores y la política de subsidios son ineficientes. Por eso el debate se genera cuando no hay una claridad a quien se dirige la ayuda o a qué tipo de actores.

Justamente para (Guayanlema, 2017) los subsidios se pueden encaminar a los beneficiarios de la oferta o de la demanda; y también en función de la cobertura que pueden ser universales o segmentados. $Y$ la categorización de la fuente de financiamiento, es también parte del debate ya que los subsidios pueden ser cubiertos por el Estado o la empresa que vende el bien o provee el servicio, a través de un fondo específico sea éste público o privado, o a través de los mismos consumidores mediante la implementación de tarifas diferenciadas. Por ejemplo, algunos consumidores cancelan precios por debajo de los costos promedios mientras que otros deben pagar precios por encima de los mismos para compensar este déficit, en este caso se habla de un subsidio cruzado (Guayanlema, 2017).

De esa manera los valores de los bienes o servicios en el mercado interno deberán ser ajustados donde una parte lo cancelará el consumidor y la diferencia del costo real lo asumirá el Estado. Si el objetivo, es ajustar el precio de un bien o servicio, el subsidio es directo cuando el Estado o la empresa prestadora paga directamente a los consumidores una parte o la totalidad del costo. Por otra parte, se habla de un subsidio indirecto si el propósito es incrementar la capacidad de gasto del beneficiario a través de la reducción del precio de un bien o servicio. Al tratarse de derivados de petróleo, se considera al subsidio como la desviación entre los precios de referencia internacional de los combustibles y los precios ex refinerías, en caso que el precio interno sea inferior al precio internacional (Mendoza, 2014). 
Figura 1. Criterios para la clasificación de subsidios

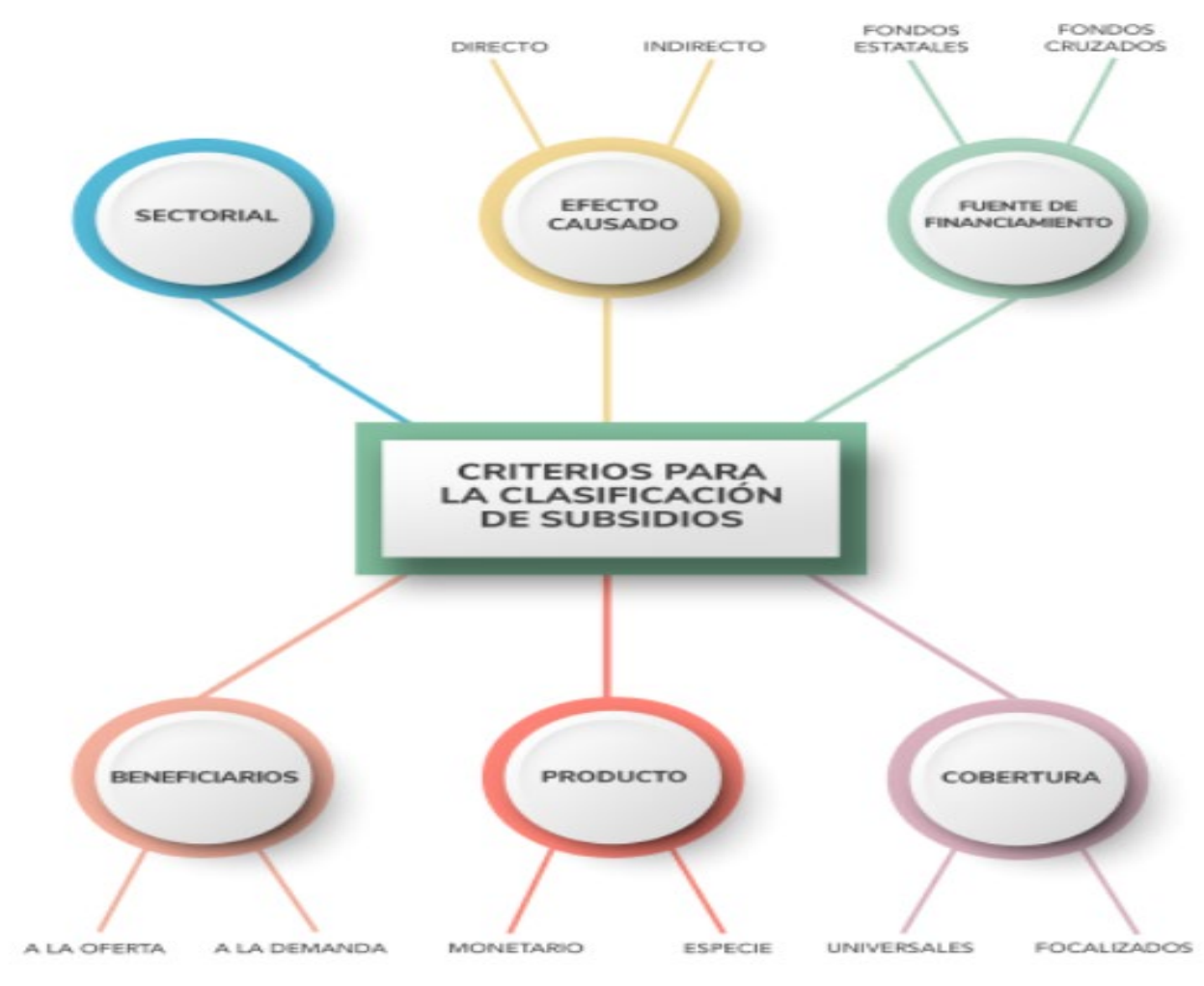

Fuente: Elaboración propia.

\section{Los precios de los combustibles en América Latina}

La mayoría de los países productores no tienen una metodología clara para fijar los precios y evitar los saldos rojos en sus finanzas. Y más aún no hay una fórmula para aplicar o medir el nivel de subsidio que se requiere, por lo que lo hace discrecional para los gobiernos de turno, y en especial de las naciones productoras del crudo. $Y$ los resultados se convierten en más problemas de liquidez y no en una forma de focalizar eficientemente la ayuda a los más necesitados.

Además, este tipo de precios bajos en los combustibles, representan una forma útil de evaluar el argumento teórico subyacente de que el petróleo y la autocracia están relacionados a través de un mecanismo de gasto rentista. $Y$ eso se suma, que cuando se lo aplica al consumo final se convierten en políticas de alto perfil fácilmente atribuibles a los gobiernos, lo cual es necesario para que los ciudadanos recompensen a los gobernantes con apoyo político a través de los mecanismos retrospectivos o de reciprocidad mencionados anteriormente. 
De hecho, los mandantes son muy conscientes de que el tamaño y el impacto de los subsidios y los cambios en el régimen de subsidios pueden ser políticamente costosos. Sin duda es un tema escamoso en cuanto a la eficiencia de la gestión pública en el Ecuador, es el relacionado a los subsidios a los combustibles. Según (Castillo, 2007) es escamoso porque van muchos años sin tomarse serias decisiones en el tema y cada vez que se lo topa o debate sobre la mesa se convierte en el primer pretexto para que nuestra frágil democracia tambalee; como sucedió en los gobiernos de Bucaram, Jamil Mahuad y Gustavo Noboa.

Por ejemplo, los ciudadanos respondieron a la decisión del ex presidente Abdala Bucarán en 1996 de intentar elevar el precio del gas y combustibles a un nivel alto, con disturbios y paralizaciones que terminaron con su mandato. Las protestas, a menudo violentas, también han acompañado reformas de subsidios recientemente planificadas en al menos una docena de otras naciones, incluyendo Sudán, Jordania, Bolivia e Indonesia (Lockwood, 2015). Incluso cuando la respuesta no es violenta, la reforma es siempre políticamente controvertido, por lo que no es sorprendente que los gobiernos rara vez implementen completamente tales planes (Varun Sivaram y Jennifer M. Harris, 2016).

Las metodologías de fijación de precios para los principales productos derivados del petróleo (gasolina, diésel oil y GLP) son diferentes en varios países de América Latina. $Y$ más cuando no todos los países en esta región son productores netos de petróleo, entonces, es conveniente conocer cómo algunos de ellos "enfrentan" la volatilidad del precio internacional del crudo, que tiene influencias directas en el fisco.

En el caso de Argentina, la fijación del precio final de los derivados del petróleo es libre, sin embargo, la Secretaría de Energía regularmente verifica y analiza la evolución de éstos. Pese a ello, los precios internos de estos productos no acompañan regularmente la cotización internacional del petróleo. Ello se explica con la presencia de los "derechos de exportación", en efecto, hasta el año 2007 se sucedieron varias modificaciones a la normativa legal referida a los derechos de exportación, la mayoría se concentraba en cambios en los porcentajes aplicados, bajo la premisa de que, incrementos en el precio internacional del petróleo deberían también beneficiar al Estado Argentino, a través de mayores porcentajes.

En enero de 2017, después de 15 años, la nueva administración dejó sin efecto las retenciones a los hidrocarburos. El Ministro de Energía firmó con las empresas del sector un acuerdo para que los precios internos convergieran a los precios internacionales. El acuerdo 
fijaba los precios de referencia para 2017 y proponía una revisión trimestral basada en el precio internacional del barril de petróleo y el tipo de cambio. Asimismo, estipulaba que si el precio internacional del barril de petróleo crudo Brent superaba durante más de 10 días consecutivos el valor de referencia previsto para el petróleo crudo local con menos un dólarbarril, esto es 54 dólares por barril, entonces quedaban suspendidos los compromisos del acuerdo a partir del mes calendario posterior. Esta condición se cumplió el 13 de septiembre de 2017, con lo que el acuerdo quedó sin efecto a partir del $1^{\circ}$ de octubre de 2017 . La suspensión del acuerdo supuso la liberalización de los precios de los combustibles, lo que elimina su revisión trimestral (Salvador, 2018).

Al momento de la liberalización, el tipo de cambio estaba en 17,70 pesos y el barril de petróleo de referencia, en 56 dólares. Desde entonces, tanto el tipo de cambio como el barril de petróleo iniciaron un sendero creciente. Entre octubre y los primeros días de febrero, el tipo de cambio aumentó $15,5 \%$ y el barril de petróleo 14 por ciento. Sin embargo, los precios de los combustibles han aumentado $24 \%$ desde su liberalización y $8 \%$ en lo que va de 2018 .

En Bolivia, la metodología incluye la fijación de precios de referencia más los márgenes de ganancia y los impuestos, sin embargo, mantiene inalterados los precios finales, porque el precio de referencia para el petróleo comercializado en el mercado interno se mantiene constante en 27.11 US $\$$ / Barril, debido a la "banda de precios" autorizada mediante Decretos Supremos 27660 y 27661 desde el año 2004. Estas normas legales establecen que cuando el precio internacional paridad exportación del petróleo en Bolivia sea superior/inferior a los 27.11/24.53, entonces el precio utilizado para calcular los precios internos de los derivados del petróleo, será el límite superior/inferior de la banda.

Brasil también aplica el régimen de libertad de precios en toda la cadena de producción, distribución y reventa de combustibles y derivados del petróleo. De forma paralela, la Agencia Nacional del Petróleo (ANP) acompaña el comportamiento de los precios de los principales productos derivados del petróleo, a través de una encuesta semanal a las principales distribuidoras y puestos de reventa, publicada en su sitio web (www.anp.gov.br). Pese a que los precios están desregulados, aún es posible conocer su estructura, dado que los participantes en la cadena son los usuales en la industria.

Y Chile no tiene ninguna ley o norma que obligue a mantener política de precios. Más bien ésta corresponde a una realidad comercial ya que se trata de un país abierto al comercio internacional. Por lo mismo, la estructura del precio paridad de importación es convenida entre la Empresa Nacional de Petróleo (ENAP) y sus clientes (las compañías distribuidoras 
mayoristas), modificándose cuando así lo requieren cambios que afecten al comercio internacional.

Según el estudio (Gutiérrez, 2017) realizado en México se desarrolló una investigación sobre los efectos de la nueva política de precios de las gasolinas y el diésel, donde se liberaron los precios a partir de enero del 2017, lo que causó un aumento en los precios.

En el estudio realizado sobre los efectos de la política de precios de la gasolina en Colombia, también se evidenció que anteriormente existía la política de ser subsidiados por el Estado. Se menciona que el gobierno realizó ajustes con la finalidad de que los precios sean puestos por el mercado para liberar recursos y así poder subsanar el déficit fiscal. Se observó que los cambios del precio están relacionados con el aumento del barril del petróleo, otro factor que se mostró fue que el subsidio que pagaba el Estado perdió su razón de ser debido a la demanda satisfecha por la hidroelectricidad. Para la aplicación del cambio de precios se utilizó la regla de Ramsey-Feldstein, concluyendo que no existe un efecto distributivo importante al momento de realizar el desmonte al subsidio, sumado a que la aplicación de la política de liberación de precios no afecta de ninguna manera a los ciudadanos (Parra, 2016).

Figura 1. El consumo de combustible fósiles por país, 2018

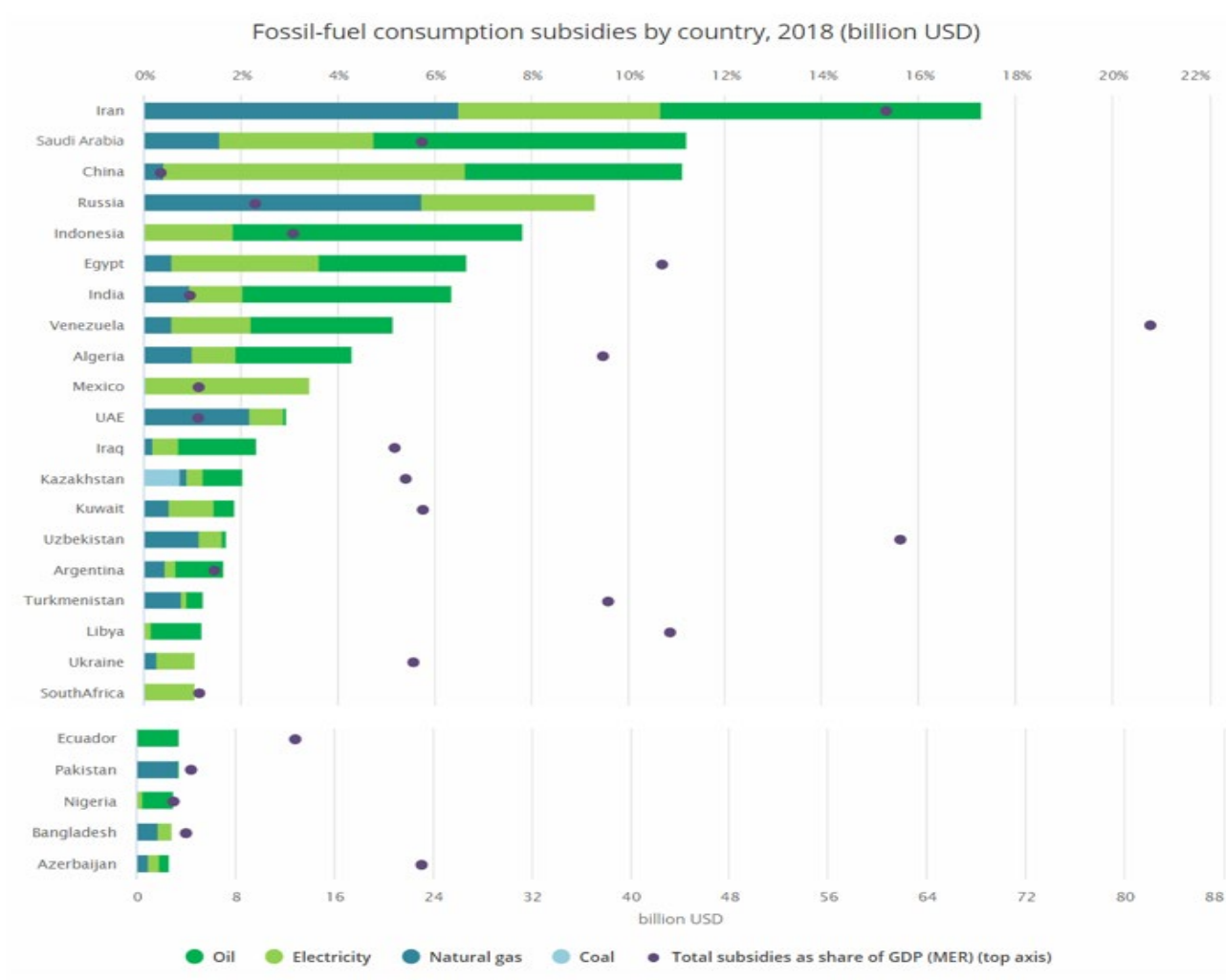

Fuente: IEA 
La medida también se amplió al precio de la gasolina extra y ecopaís. El Decreto ejecutivo 619 se dispuso que desde el 26 de diciembre del 2018 se incrementará de 1,48 a 1,85 dólares el precio del galón final a los consumidores. Este producto todavía tiene una carga de subsidio de casi 46 centavos de dólar y sigue fijo (COMERCIO, 2018).

\section{MATERIALES Y MÉTODOS}

En la presente investigación se aplica el enfoque cuantitativo, debido a que las variables se analizan por medio de la medición numérica y el uso de herramientas estadísticas, para poder establecer patrones de comportamiento y realizar correlaciones entre ellas y determinar los efectos de los subsidios de gasolina en el Ecuador.

Se trata de una investigación descriptiva y correlacional, debido a que se busca de forma adecuada especificar características del fenómeno a investigar para poder describir tendencias del grupo de datos que forman las variables y correlacional porque se analiza la relación del subsidio de la gasolina con la demanda y precio del mismo.

El diseño de la investigación aplicada es no experimental, ya que se toman los datos de instituciones públicas del Ecuador, para realizar el análisis por medio de la observación sin implicar manipulación de las variables de estudio. También se aplica el corte longitudinal, ya que en el análisis de los datos se realiza la valoración de los cambios que tienen en el tiempo el subsidio, demanda y precio de la gasolina.

La herramienta de recolección de datos utilizada es la investigación documental, ya que para poder obtener información de las variables de estudio se procede a la recopilación de informes oficiales que reposan en las instituciones del Estado. Es decir, la información se obtendrá por medio de documentos oficiales de la empresa pública PetroEcuador en el periodo del 2018 hasta julio del 2019, con respecto a subsidios de derivados y combustibles, así como también de precio y demanda de gasolina. La misma que la reporta de manera anual y mensual en la página institucional de la entidad.

El método que se utiliza en la investigación es el deductivo, cuya particularidad radica en la observación del fenómeno a estudiar partiendo de premisas lógicas. Es decir, la finalidad de este método es partir de lo general por medio de la revisión literaria a lo particular donde se concluye los fenómenos o hechos concretos (Ortiz \& Ruiz, 2017). 
Tabla 1. Variables 1

\section{Variables_1}

\begin{tabular}{ll}
\hline Fuente & PetroEcuador \\
\hline Variable independiente & Precio de barril de petróleo \\
\hline Variables dependiente & Liberación de los precios de combustible \\
\hline Periodicidad & Mensual \\
\hline Rango & Enero 2018 a julio 2019 \\
\hline
\end{tabular}

Tabla 2. Variables 2

variables_2

\begin{tabular}{ll}
\hline Fuente & PetroEcuador \\
\hline Variable independiente & Demanda de los combustibles \\
\hline Variables dependiente & Subsidio de los combustibles \\
\hline Periodicidad & Mensual \\
\hline Rango & Enero 2018 a julio 2019
\end{tabular}

\section{El mercado de los combustibles y sus tendencias}

La demanda de la gasolina muestra un comportamiento en el periodo de estudio de enero a diciembre del año 2018 a julio del 2019 con un mínimo de 2'267,848 barriles y un máximo de 2'743,270. Se nota un incremento importante al través del tiempo, pero su punto de inflexión más fuerte fue en enero cuando la gasolina eco y extra cambiaron de precio. En cambio, la súper sigue una tendencia a la baja debido a la liberalización de su precio y que su cotización cambia mensual de acuerdo al comportamiento del precio del barril de petróleo en los mercados internacional.

A pesar de las medidas aplicadas en una liberalización total en la en un segmento alto y otra parcial para la variedad eco y extra, la demanda sigue aumentando debido al incremento del parque automotor. Al inicio del aumento de los precios, los consumidores redujeron sus demandas, pero en el corto plazo volvieron a sus mismos niveles. Solo la súper se redujo casi a la mitad su consumo mensual. Más aún cuando el precio se fija de acuerdo al comportamiento de la cotización internacional.

Si se analiza la demanda de extra y eco se nota que su aumento está relacionado con la reducción de súper, pues los clientes han migrado a esos tipos de combustibles por la 
diferencia de precios que bordea entre 1, 10 y 1,30 dólares el galón. Si el promedio de galones que requiere un vehículo para llenarse es de 20 la diferencia es significativa para el bolsillo de cualquier de los cerca de 2 millones de conductores.

Con estas medidas se buscó reducir los desembolsos en subsidios en combustibles, pero en la práctica no se logró. Si bien, antes de los decretos ejecutivos, cada vez que el precio del barril del crudo aumentaba los subsidios también se elevaban pues había una relación proporcional. Sus niveles de correlación se ubican entre 0,92 y 0,90.

Figura 2. Comportamiento de la demanda de combustibles

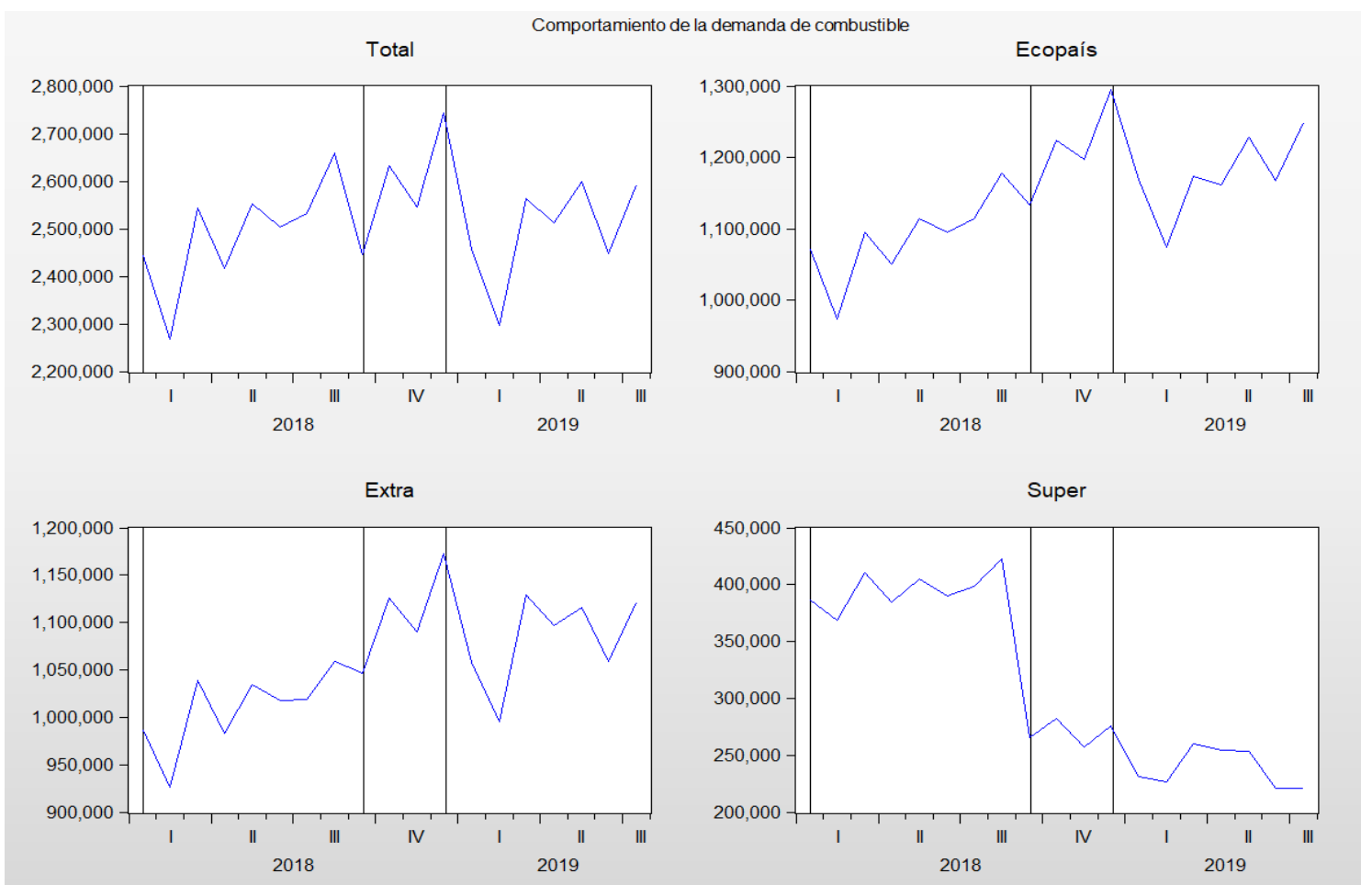

Fuente: Elaboración propia a partir de Petroecuador

Y eso incluía en todos los derivados como diésel y gas licuado. Solo en el 2018 se destinó en subsidios para los derivados 1.914 millones de dólares, de los cuales 916 millones solo fue para los consumidores de diésel y 630 millones para las gasolinas eco, súper y extra. Es más, si se comprara todos los subsidios con el Presupuesto General del Estado, se ubica en el $9,93 \%$ con la tendencia en aumenta, ya que hasta el 2017 se estaba disminuyendo su participación con el 8,38\% y siendo el 2007 el más alto con el 32,1\% del presupuesto. 
Eso demuestra también que los subsidios de los derivados están relacionados con el mercado internacional del crudo. $Y$ hasta el momento, se puede señalar que las medidas no han hecho que se reduzca el gasto en subsidio ya que se mantiene bordando los 120 millones mensuales en el 2019 con tendencia a seguir subiendo, mientras que en el 2018 se ubicó en 180 millones. Eso implica que en los próximos meses los valores pueden nivelarse al de los periodos anteriores.

Figura 3. La relación entre las variables
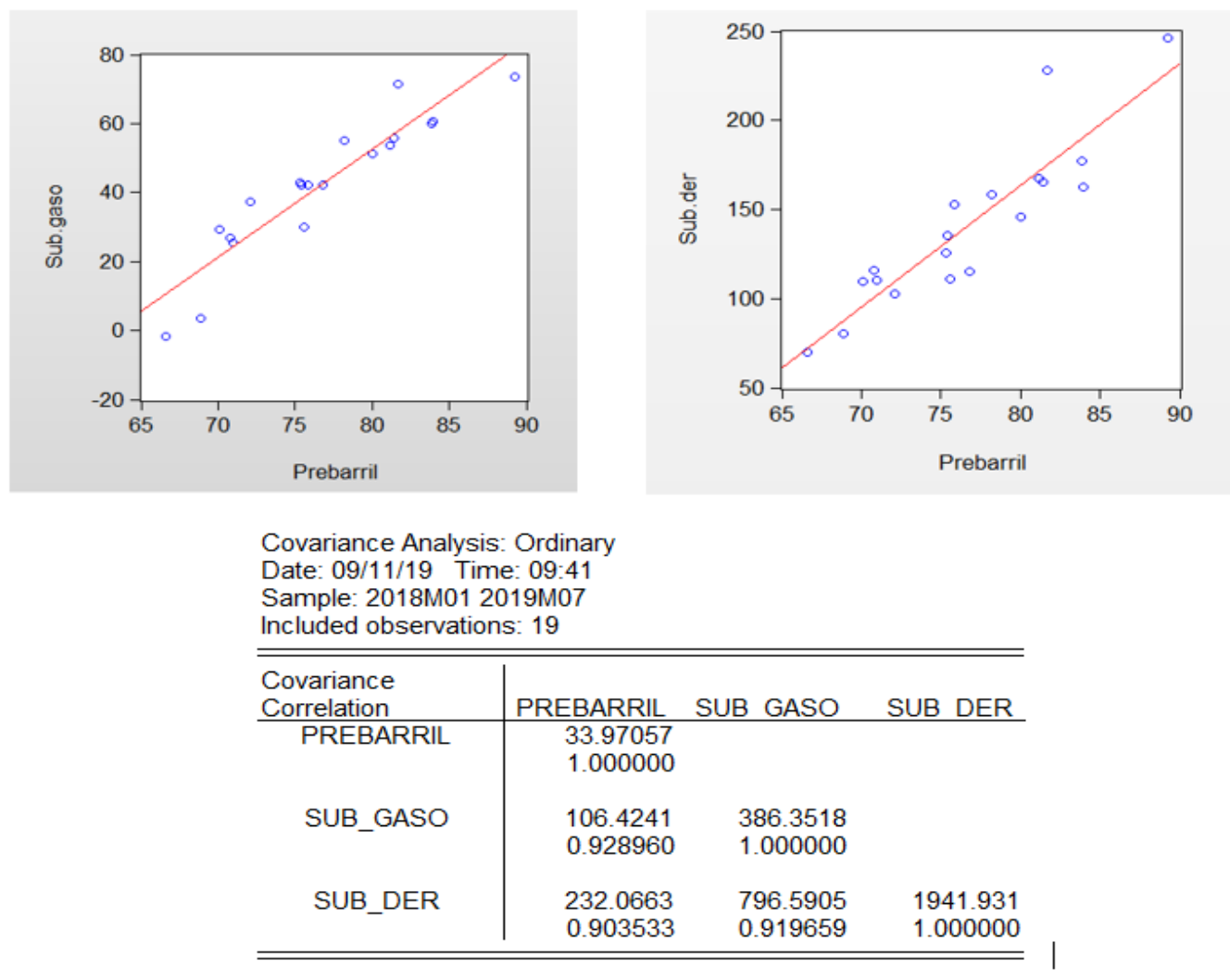

Fuente: Elaboración propia a partir de Petroecuador

De los diferentes componentes del gasto de subsidios, resalta principalmente el destinado al campo de combustibles (gasolinas, diésel y gas licuado de petróleo o GLP), el cual siempre ha ocupado un importante porcentaje del rubro total de los subsidios, y en los últimos años ha alcanzado o superado la mitad del total del presupuesto, tal como puede apreciarse en el cuadro subsiguiente (Miño, 2018). 
Gráfico 4. El peso de los subsidios en el Presupuesto General del Estado

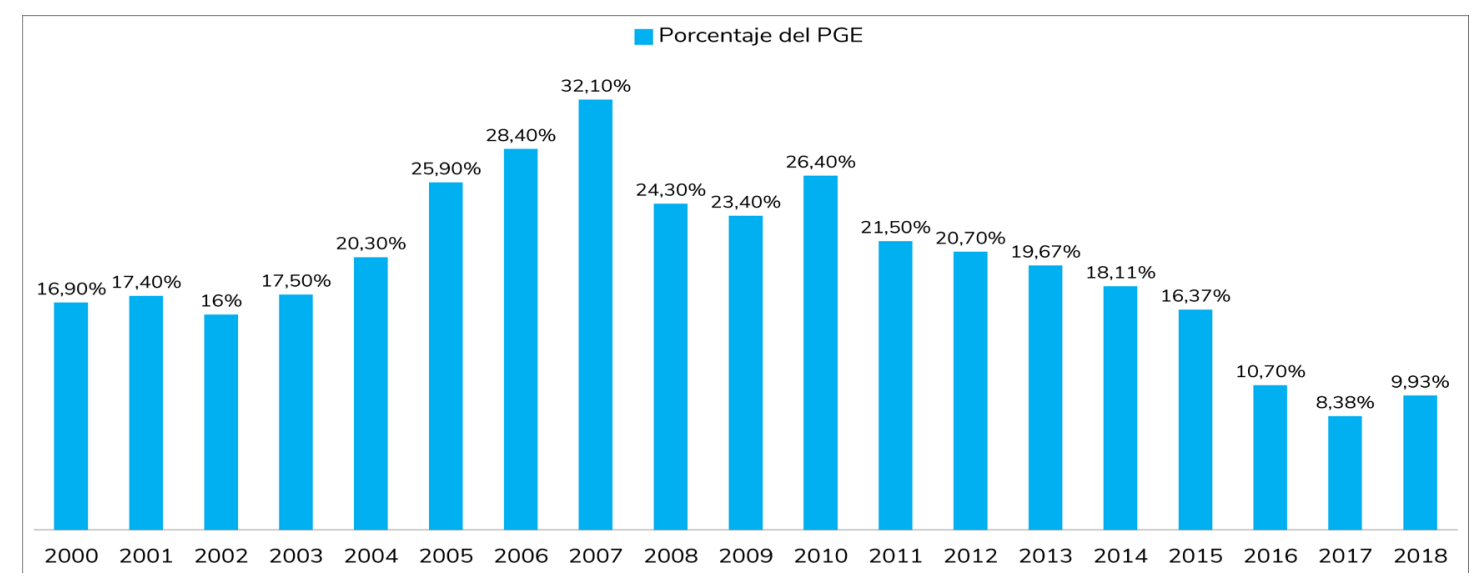

Fuente: ILDIS

Y si se compara con más detalle, es decir, si ve ve la demanda de los combustibles y se relaciona con los subsidios, se dan pistas de que la medida no generó el impacto deseado ya ni se focalizó y se sigue subsidiado a las diferentes clases sociales y no a los que realmente lo requieren en el mercado.

Gráfico 5. Comportamiento de los subsidios de los combustibles

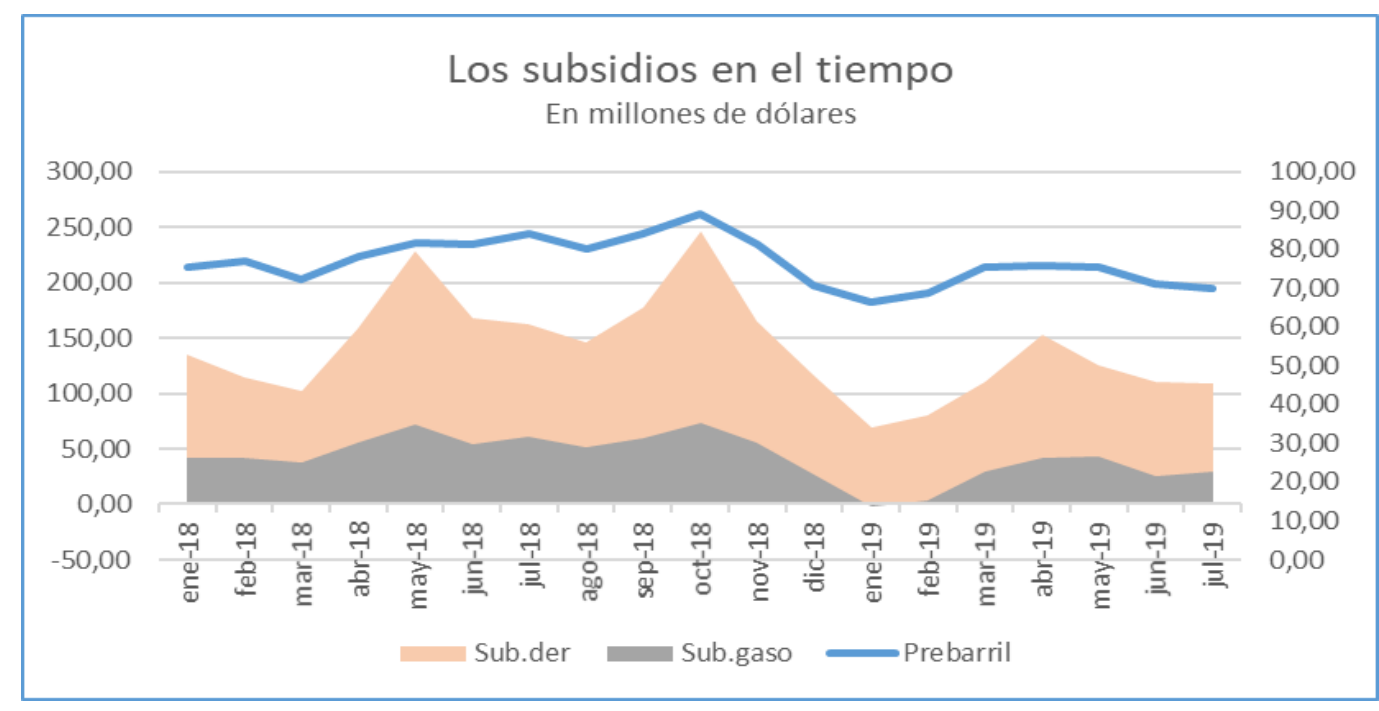

Fuente: Elaboración propia a partir de Petroecuador

En definitiva los subsidios no fueron creados con el ánimo de mantener y una población poco pudiente, que más bien son solo una solución momentánea, debe existir una práctica que solucione los problemas de fondo, ya que si nos mantendríamos con ellos va a llegar un momento en que no se van a poder mantener, se deben generar un buen clima y la 
estabilidad necesaria para la inversión y que sean generadoras de oportunidades de empleo que sería lo que también mejore al ingreso y ahorro de la población, y para garantizar esto debe existir las correcciones necesarias para que el objetivo por el cuál fue creado tal subsidio se cumpla y llegue a las personas para las cuáles está destinado.

Gráfico 6. La demanda de los combustibles en el mercado local

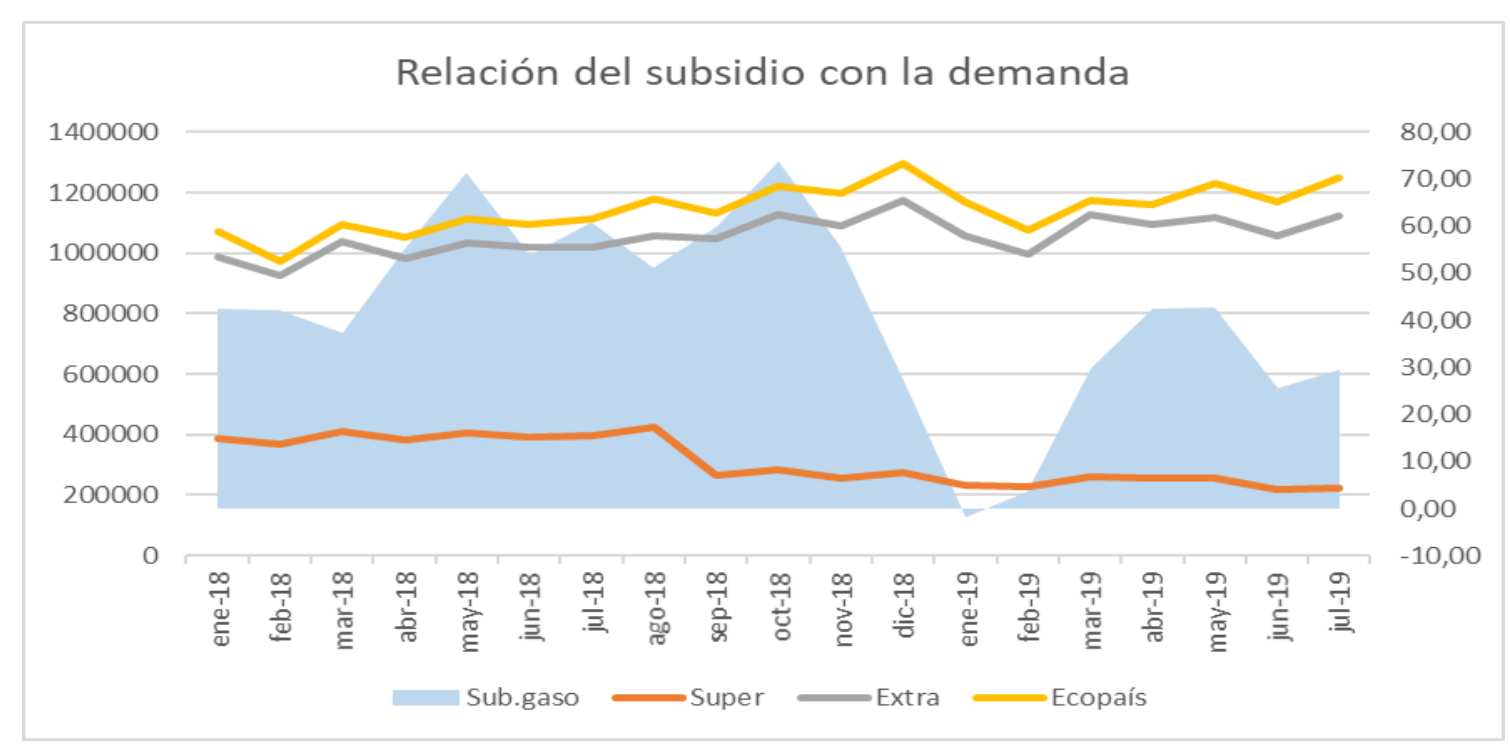

Fuente: Elaboración propia a partir de Petroecuador

\section{CONCLUSIONES}

Para que un subsidio en términos económicos justifique su eficiencia y efectividad debe mantener entre varias las siguientes características basados en principios para así garantizar que la población que demanda dicho subsidio sea a quién en verdad llegue:

Transitoriedad, es decir, que se otorguen mientras dure la condición que dio origen a la creación de dicho subsidio.

Focalización, es decir, que estén destinados o canalizados a las personas necesitadas y que se identificaron como potenciales receptores.

Eficiencia, es decir, que llegue siempre de forma progresiva más a los más pobres y menos a los menos pobres, teniendo en cuenta que debe tener un mecanismo de control barato.

Económicamente factible, es decir, tener en cuenta la escasez de los recursos públicos y las diversas necesidades de la población, el financiamiento del subsidio no debe afectar la sostenibilidad fiscal. 
Pues las actuales medidas no lograron su propósito ya que por eliminar un subsidio de un combustible se aumentó el gasto de otro derivado como es el de la extra y eco. Es verdad, que una eliminación brusca e inmediata de los incentivos generará un impacto social fuerte, ya que se incrementarán los costos de todos los bienes y servicios de la economía.

Dentro de las estrategias analizadas también se debe insistir que si se va a incrementar los precios debería ser de forma gradual y acompañada de medidas compensatorias. A eso sumar el incentivo de uso de tecnologías más eficientes donde involucre las fuentes de energía renovable.

Y comparto con otros investigadores que si se mantiene una política de subsidios a los combustibles en forma anti técnica se podrá convertir en una barrera para la implementación de medidas de eficiencia energéticas renovables.

\section{REFERENCIAS BIBLIOGRÁFICAS}

Cheon, A.; Urpelainen, J. \& Lackner, M. (2013). Why do governments subsidize gasoline consumption? An empirical analysis of global gasoline prices, 2002-2009. Energy Policy, 10.

Atkinson, A. (2015). Desigualdad: ¿Qué podemos hacer? México: Fondo de cultura económica.

Clements, B.; Coady, D.; Fabrizio, S.; Gupta, S.; Alleyne, T. y Sdralevich, C. (2013). Energy Subsidy Reform: Lessons and Implications. Washington: International Monetary Fund.

Castillo, J. (2007). Una nota acerca de los subsidios, la política y la economía. Cuestiones Económicas, 11.

COMERCIO (26 de Diciembre de 2018). Alza de gasolina extra entró en vigencia pasado el mediodía del 26 de diciembre, con publicación en Registro Oficial. EL COMERCIO, p. 1.

Fails, M. (2019). Fuel Subsidies Limit Democratization: Evidence from a Global. International Studies Quarterly, 10.

Guayanlema, S. E. (2017). Balance y proyecciones del sistema de subsidios energéticos en el Ecuador. Quito: ILDIS. 
Poveda, G.; Carrillo, F. y Castro, F. (2018). Impacto social ante eliminación del subsidio a los combustibles en Ecuador. Observatorio de la Economía Latinoamericana, 16.

Gutiérrez, R. (2017). La simple aritmética de la nueva política de precios de las gasolinas y el diesel. Economía Informa, 23.

Lockwood, M. (2015). Fossil Fuel Subsidy Reform, Rent Management and Political Fragmentation in Developing Countries. Journal New Political Economy, 19.

Mendoza, M. (2014). Panorama preliminar de los subsidios y los impuestos a las gasolinas y diésel en los países de América Latina. Santiago: CEPAL.

Miño, F. M. (2018). Subsidios a los combustibles en Ecuador: elementos y dimensiones para una discusión argumentada. Quito: ILDIS.

OLADE. (2007). Focalización de los Subsidios a los combustibles de América Latina y El Caribe. Quito: OLADE.

Parra, J. (2016). La política de precios de la gasolina en Colombia: Antecedentes, impacto distributivo y su relación con la crisis fiscal. Munich Personal RePEc Archive, 36.

Salvador, P. (2018 de febrero de 2018). Precios de los combustibles: de la regulación a la liberalización. Infobae, p. 1.

Varun, S. \& Harris, J.M. (2016). Sustaining Fuel Subsidy. New York: Council on Foreign Relations. 